\title{
A gastronomia e os megaeventos esportivos na construção da marca "Brasil": aproximações entre copa do mundo, turismo e relações públicas
}

\author{
Gastronomy and the sports mega-events in the \\ construction of the "Brasil" brand: proximities \\ between world cup, tourism and public relations
}

\section{La gastronomía y los megaeventos deportivos en la construcción de la marca "Brasil": aproximaciones entre copa del mundo, turismo y relaciones públicas}

\section{Anderson Gurgel Campos}

- Doutorando do Programa de Pós-Graduação em Comunicação e Semiótica da Pontifícia Universidade Católica de São Paulo (PUC-SP), onde estuda as imagens do esporteespetáculo

- Mestre em Comunicação e Semiótica pela PUC-SP

- Graduado em Jornalismo pela Universidade Estadual Paulista (Unesp)

- Professor do Curso de Comunicação Social da Universidade de Santo Amaro (Unisa) e na pós-graduação do Centro Universitário FMU

- É autor do livro Futebol S/A: a economia em campo (Saraiva, 2006)

- andersongurgel@hotmail.com

Helena Maria A. Jacob

- Doutoranda do Programa de Pós-Graduados em Comunicação e Semiótica da Pontifícia Universidade Católica de São Paulo (PUC-SP), com pesquisa sobre ambientes midiáticos da gastronomia

- Bolsista Capes-Prosup - bolsa parcial

- Mestre em Comunicação e Semiótica e graduada pela PUC-SP

- Graduada em Jornalismo pela Universidade Estadual Paulista (Unesp)

- Docente da Faculdade Cásper Líbero (Facásper) e do Centro Universitário Fecap (Fundação Escola de Comércio Álvares Penteado)

-h.jacob@uol.com.br 
Neste artigo analisa-se o papel da gastronomia como elemento de representação simbólica do país, a partir da marca "Brasil”. Com base nos conceitos de imagem corporativa, identidade e marca, desenvolve-se uma reflexão sobre como os pratos típicos nacionais podem contribuir para o fortalecimento da imagem brasileira no exterior. Discute-se o papel da gastronomia como sistema da cultura e, por consequência, como as relações públicas podem gerar a produção de textos simbólicos que ajudam a compor a imagem organizacional do Brasil na mídia, a partir dos megaeventos esportivos, como a Copa do Mundo de Futebol e os Jogos Olímpicos.

PALAVRAS-CHAVE: MEGAEVENTOS • GASTRONOMIA • COPA DO MUNDO • MARCA "BRASIL" • RELAÇÕES PÚBLICAS

Abstract

This article analyzes the role of gastronomy as an element of symbolic representation of Brazil, from the concept of the "Brasil" brand". Based on the concept of corporate image and of brand identity one develops a reflection on how national dishes can contribute to the strengthening of the Brazilian image abroad. We discuss the role of gastronomy as a system of culture and, consequently, how public relations can generate the production of symbolic texts that help make up the organizational image of Brazil in the media, from mega-events such as the Soccer World Cup and the Olympic Games.

KEYWORDS: MEGA-EVENTS • GASTRONOMY • WORLD CUP • "BRASIL" BRAND • PUBLIC RELATIONS

\section{Resumen}

En este artículo se analiza el papel de la gastronomía como elemento de representación simbólica del país, a partir de la marca "Brasil". Tomando como base los conceptos de imagen corporativa, identidad y marca, se desarrolla una reflexión sobre cómo los platos típicos nacionales pueden contribuir al fortalecimiento de la imagen brasileña en el exterior. Se discute el papel de la gastronomía como sistema de la cultura y, en consecuencia, cómo las relaciones públicas pueden generar la producción de textos simbólicos que ayudan a componer la imagen organizacional de Brasil en los medios, desde megaeventos como la Copa Mundial de Fútbol y los Juegos Olímpicos.

PALABRAS CLAVE: MEGAEVENTOS • GASTRONOMÍA • COPA DEL MUNDO • MARCA “BRASIL" • RELACIONES PÚBLICAS 
$A^{\mathrm{p}}$ pesar de todos os contratempos na preparação do Brasil para ser sede da Copa do Mundo de 2014, o secretário geral da Federação Internacional de Futebol Associado (Fifa), Jérôme Valcke, é enfático em pontuar que há grande interesse de gente de todos os cantos do planeta em vir ao país para participar desse que é o maior evento futebolístico e que ocorre a cada quatro anos. Em um encontro com a imprensa, realizado no segundo semestre de 2011, quando este artigo estava sendo desenvolvido, ele afirmou: "Todos querem vir ao Brasil. Se começássemos a vender ingressos amanhã, tenho certeza de que já venderíamos muitíssimos"1.

O contexto em que Valcke fez tal afirmação era o de um momento de grande tensão entre Fifa, Governo Brasileiro e Comitê Organizador Local (COL), com preocupação por parte da entidade com os prazos para a conclusão das obras fundamentais para a copa do mundo, com a construção das arenas, da infraestrutura necessária para receber os turistas internacionais e, até mesmo, os nacionais, que devem se deslocar pelo país para assistir aos jogos. A mensagem que a entidade máxima do futebol passou naquele momento era de que, mesmo com os contratempos, a imagem internacional do Brasil atrairia turistas e permitiria prever bastante sucesso com esse quesito na organização do mundial.

Partimos dessa convicção do secretário geral da Fifa, para tentar refletir neste artigo sobre a imagem internacional do Brasil nesse período pré-copa do mundo e de que maneira o desenvolvimento de ações de relações públicas, envolvendo o imaginário de Brasil na comunidade internacional, pode contribuir para aperfeiçoar ainda mais essa estratégia. É importante pontuar que o grupo de pessoas a que nos referimos é aqui entendido como uma fatia da população global com acesso à informação e com poder aquisitivo para fazer turismo internacional e beneficiar-se da possibilidade de conhecer outras culturas e experienciar realidades de países distintos dos seus de origem.

Também é importante pontuar que vamos focar neste artigo a gastronomia como uma forma de entender e aperfeiçoar as ferramentas de construção de uma imagem do país, a partir da realização de um megaevento esportivo. Não queremos dizer que essa é a única forma, muito pelo contrário, mas acreditamos - e tentaremos mostrar aqui - que os elementos do universo gastronômico permitem desenvolver ambientes de relacionamento e experiência diferenciados para a construção imagética de um sentido de Brasil e de brasilidade desejados pelas ações de relações públicas em nível de governo, COL e instituições com interesses afins.

Por fim, cabe pontuar que, para a breve reflexão que pretendemos desenvolver neste trabalho, não teremos condições de fazer um estudo detalhado da ques-

1 A afirmação foi amplamente disseminada na imprensa, mas deixamos aqui a referência da reportagem publicada no site da Fifa: <http://pt.fifa.com/worldcup/preliminarydraw/news/newsid=1482363/index. $\mathrm{html}>$. Acesso em: 01/11/2011. 
tão. Por isso, propomos fazer a aproximação teórica do conceito de megaeventos esportivos com os de gastronomia e com as práticas de relações públicas, principalmente no que se refere à construção da imagem e marca de um país. Para observar alguns casos que já foram ou estão sendo desenvolvidos no momento pré-Copa do Mundo de 2014, destacaremos alguns casos referentes à Copa da África do Sul de 2010, como breve comparação, e algumas possíveis ações a serem desenvolvidas ou aperfeiçoadas por entidades brasileiras para o segundo mundial de futebol que será realizado em solo nacional.

\section{GASTRONOMIA NO CAMPO SIMBÓLICO}

O futebol retratado no universo audiovisual brasileiro casa com festas de exacerbação de alegria, com muito samba e com comida, geralmente feijoada ou churrasco. O churrasco é tão inerente ao universo das copas do mundo que é um dos termômetros de sucesso do evento no Brasil: nas festas que são organizadas para ver os jogos da seleção nacional esse tipo de festa é uma das preferidos. Outro prato típico que também faz parte das comemorações coletivas e envolve certa fartura de carne é a feijoada. Por esses exemplos, não dá para ignorar que feijoada, churrasco brasileiro, caipirinha e tantos outros pratos e bebidas típicas fazem parte da curiosidade de grande parte dos turistas que chegam ao país.

Particularmente a feijoada, que é um mistura de pés, rabo e orelhas de porco, feijão, legumes e carnes nobres, como carne-seca, paio, linguiça, costeleta de porco e lombo, como é popularmente convencionada (Algranti, 2000, p. 228), é um símbolo da comida e cultura brasileiras, estando presente nas mesas e mentes dos nativos e dos turistas. De certa forma, a feijoada projeta-se para o mundo, como uma forma de simbolização da comida e, por consequência, do jeito de ser brasileiro (e não só à mesa). Por isso, podemos dizer que, no Brasil, são poucas as unanimidades, mas não dá para negar que a seleção brasileira, o samba e a feijoada estão entre elas.

Interessa-nos, contudo, observar que o prato, como um exemplo típico da culinária nacional, também tem grande proximidade com o selecionado verde-amarelo. A começar pelo fato de que, não se passa uma campanha do selecionado canarinho sem que a imprensa divulgue que, junto com o time, foram embarcados também quilos e mais quilos de feijão preto. Quando possível, até mesmo a tradicional feijoada é celebrada na concentração nacional, como uma reportagem de O Estado de S. Paulo, da Copa América de 2011, na qual se destaca: "Neymar e seleção brasileira comem feijoada na concentração ${ }^{2}$.

2 Um caso recente dessa gula gastronômica entre os craques da seleção brasileira aconteceu na Copa América de 2011. Várias reportagens registraram esse episódio. Umas delas foi do jornal $O$ Estado de $S$. Paulo, que apontou: "Neymar e seleção brasileira comem feijoada na concentração da Copa América". Ver: <http://www.estadao.com.br/noticias/esportes,neymar-e-selecao-brasileira-comem-feijoada-na-concentracao-da-copa-america,740614,0.htm > . Acesso em: 30/08/2011. 
Desse assunto, o que nos interessa aqui, particularmente, é que, tendo o futebol brasileiro em geral e a seleção nacional como veículos estratégicos, imagens da cultura e da comida brasileira viajam pelo mundo, junto com a fama do selecionado verde-amarelo. Acreditamos que, a partir daí, tais imagens simbólicas podem ser amplamente utilizadas pela indústria do turismo para representar e/ou fortalecer a imagem do Brasil no exterior.

Por ser uma das manifestações culturais mais viscerais e de maior importância no cotidiano humano - afinal, todos os indivíduos precisam comer para viver -, a cozinha representa um universo farto na construção de imagens capazes de representar um determinado país. Acreditamos que, em tal processo de construção das imagens, a utilização dos elementos da gastronomia típica é um fator de atração e fortalecimento das imagens que constroem o imaginário de Brasil, principalmente junto ao público do exterior.

O Brasil, por meio dos governos federal, estaduais e municipais e do COL, tem todo interesse em atuar na construção de uma imagem positiva de si próprio para a opinião pública internacional. Essa questão que sempre é crítica torna-se ainda mais importante a partir do momento que o esporte passa a ser uma das principais pautas nacionais, com a realização em solo brasileiro da Copa do Mundo de 2014 e também dos Jogos Olímpicos de 2016.

Dentro dessa estratégia, na Copa da África do Sul, em 2010, por exemplo, a Agência Brasileira de Promoção de Exportações e Investimentos (Apex-Brasil) desenvolveu o projeto "Casa Brasil 2014", um local de relacionamento onde os visitantes, em grande parte turistas estrangeiros e líderes globais que estavam no país-sede daquele mundial, podiam ter contato com produtos, representantes e ideias da cultura brasileira. Entre as ações que lá foram realizadas ocorreu uma atividade chamada "Sabores do Brasil", na qual eram realizadas degustações de produtos brasileiros, como café, frutas, bebidas, entre outros ${ }^{3}$. Tais ações são importantes na preparação da identidade do Brasil enquanto país-sede da Copa do Mundo de 2014.

Nesta análise defendemos que os elementos da cultura nacional, entre os quais a gastronomia típica, podem ser excelentes elementos para a construção de uma imagem positiva do país e contribuir para geração de planos de comunicação eficientes para os profissionais de relações públicas que trabalharem tanto na construção desse megaevento quanto de outros (como a Olimpíada do Rio de Janeiro em 2016).

3 Veja "Apex promove produtos brasileiros na África do Sul durante a Copa do Mundo". <http://www. apexbrasil.com.br/portal/>. Acesso em: 30/08/2011. 


\section{MARCA “BRASIL”: IMAGEM E CULTURA}

Dentro das discussões de construção marcária, um conceito que vem ganhando espaço atualmente é o de marca-país. Para fazer uma breve reflexão sobre como surge essa questão, cabe lembrar que vivemos em uma sociedade do espetáculo, como aponta Debord (1997, p. 13-25):

Toda vida das sociedades nas quais reinam as modernas condições de produção se apresenta como uma imensa acumulação de espetáculos. Tudo o que era diretamente vivido se afastou numa representação. (...) O espetáculo não é um conjunto de imagens, mas uma relação social entre pessoas, mediada por imagens. (...) O espetáculo é o capital a um tal grau de acumulação que se torna imagem.

Seguindo a genial reflexão desse pensador, a de que o espetáculo é uma relação de pessoas mediada por imagens, lembramos que o conceito de marcas possui uma relação muito próxima com o de imagens. José E. de Oliveira Menezes (2010, p. 625), ao construir um conceito de imagem na Enciclopédia Intercom de comunicação, relaciona-o com "semelhança e representação", que são as definições mais comuns para esse termo. Contudo, o pesquisador, ao longo da sua conceituação, lembra que, entre os teóricos da imagem, há várias maneiras de se classificá-la. Para um deles, Christoph Wulf (apud Menezes, 2010, p. 625), há "pelo menos três maneiras: imagem como presença mágica, imagem como representação mimética ou imitação criativa e imagem como simulação técnica”. Para o entendimento do conceito de marca, cabe lembrar que, num mundo midiático, as imagens tornam-se cada vez mais "imagens complexas", como defende Josep Català (2005), outro teórico da área. E, por isso, acreditamos que a ideia de uma imagem-marca de um país acaba se dando pela fluidez das várias formas de manifestação da imagem, como vistos na classificação de Wulf.

Após essa reflexão sobre imagem, cabe fazer uma breve reflexão sobre imagem da marca, outro ponto relevante para este artigo. O pesquisador Celso Figueiredo Neto (2010, p. 655-6), também na Enciclopédia Intercom de Comunicação (2010, p. 655-6), explica que esse conceito refere-se a um "conjunto de signos que compõem a representação de uma determinada instituição, empresa, produto ou serviço diante dos indivíduos ligados direta (colaboradores) ou indiretamente (fornecedores, clientes, imprensa, público em geral) a ela”.

A partir da reflexão acima e na relação com as ideias de Debord - de uma sociedade espetacular, na qual as relações se dão por meio das imagens - é que fazemos a associação do conceito de imagem da marca, oriundo do mundo corporativo, com a ideia de uma imagem da marca de um país. Na sociedade imagética da tela total, como diria Baudrillard (2005), a tomada de conhecimento do mundo e das coisas se dá a partir das telas. No mundo das imagens e das telas, lugares, pessoas, coisas, empresas, tudo acaba reduzido à bidimen- 
sionalidade, na qual representações imagéticas de países, empresas ou mesmo pessoas acabam sendo postas em um mesmo plano.

Por isso, cada vez mais as imagens deixam de ser meras representações, parecendo ganhar vida. Sobre elas, no mundo das marcas, Figueiredo Neto (2010, p. 655) nos lembra que

marcas são entidades multidimensionais. (...) A imagem de uma marca é composta pelo conjunto de experiências por ela proporcionadas, sendo aquela propagada pela publicidade, projetada pelo design de embalagem e [pelo] design de produto, somada a todas as experiências anteriores dos indivíduos para com aquela marca que compõe sua imagem.

Na concepção apresentada pelo pesquisador, o que está em questão é a ideia de organização, já que a as marcas são "geradas na cúpula das empresas e desdobradas ao longo de todos os níveis hierárquicos as características tangíveis e intangíveis da marca vão se construindo dentro da empresa e dela para seus stakeholders" (Figueiredo Neto, 2010, p. 655). Contudo, pelas teorias da imagem, vistas anteriormente, não é difícil compreender como, na era do espetáculo, a concepção de marca também pode ser estendida a um país.

Em diálogo com essa percepção, estudos do Anholtz-GMI, que desenvolve uma pesquisa chamada "National Brands Index", indicam que, "se os países do mundo fossem transformados em marcas comerciais, o Brasil seria dono da $15^{\mathrm{a}}$ marca mais forte do planeta”. Essa pesquisa é um indicador de que há uma relação direta entre visitar um país com sentimentos positivos ligados a produtos, à cultura e população. Sendo assim, podemos destacar:

Os organizadores do estudo afirmam que a análise desta situação hipotética se torna cada vez mais necessária, uma vez que o fenômeno da globalização faz as pessoas observarem os países como se fossem produtos à venda, à medida que aproxima e intensifica a competitividade entre as nações, que dia após dia lutam de maneira mais agressiva [por] "atenção, respeito e confiança” de investidores internacionais, turistas e consumidores. Pois neste ranking, que contempla 25 países e tem a Austrália como primeira colocada, o Brasil aparece em posição intermediária, imediatamente atrás do Japão $\left(14^{\circ}\right)$ e na frente do México $\left(16^{\circ}\right)$ e de nações como Índia $\left(18^{\circ}\right)$, Coreia do Sul $\left(20^{\circ}\right)$, China $\left(21^{\circ}\right)$ e Rússia $\left(24^{\circ}\right) .(\ldots)$ O National Brands Index foi calculado com base em opiniões de dez mil consumidores a respeito de seis áreas específicas: turismo, força das exportações, confiabilidade do governo, vontade de investir ou morar no país, relevância da cultura e avaliação da população. De acordo com a pesquisa, a Austrália conseguiu o primeiro lugar do ranking principalmente pelos bons resultados alcançados nos componentes de turismo, investimentos, e população. Por outro lado, variáveis como cultura e exportação obtiveram votações desfavoráveis. 
Como exemplo da consolidação desse conceito, observamos o amplo destaque dado à divulgação do Ranking Country Brand Index (CBI) de 2011, da consultoria em marcas FutureBrand. Por esse estudo,

o Brasil subiu dez posições em um ranking (...) que avalia a força da "marca" de cada país no exterior (...) O ranking busca avaliar como cada país é visto por pessoas no exterior. (...) No ranking de 2011 (...) o Brasil ocupa a $31^{\text {a }}$ posição em uma lista de 113 nações. Entre os 50 países do topo da lista, o Brasil foi o que mais cresceu no ranking. Na América Latina, o Brasil fica atrás apenas da Costa Rica, que está em $24^{\circ}$ lugar. No ranking anterior, de 2009 , o Brasil ocupava a $41^{\text {a }}$ posição (UOL, 11/11/2011).

A reportagem do portal UOL lembra que, "depois de garantir a Copa e os Jogos Olímpicos, a posição do país no ranking geral saltou dez posições, tornando o Brasil uma estrela ascendente no índice geral”. A seguir, vamos analisar o papel dos megaeventos na construção de marca de país.

\section{MEGAEVENTOS ESPORTIVOS COMO MANIFESTAÇÃO DA CULTURA}

No caso dos megaeventos esportivos, o que ocorre é um tipo de consórcio no qual o COL gerencia a organização de um evento que tem entre os interessados representantes da Fifa e dos governos federal, estadual e municipal das cidades-sede - sendo que, no modelo ideal, são esses homens públicos representantes do interesse da população local.

Para abordar o conceito de megaeventos, precisamos lembrar que o esporte, na contemporaneidade, é um espetáculo e, como tal, gera um "show de imagens": jogos, jogadores, jogadas, façanhas e narrativas, arenas, torcedores, produtos, dirigentes, políticos, produtos e celebridades do (e no) esporte são alguns dos itens fundamentais dessa grande fonte geradora de imagens e imaginários que constroem um sistema de práticas e de sentido inseridos no ambiente capitalista do trabalho e da geração de interesses econômicos.

Vamos trabalhar com o Atlas do esporte no Brasil (DaCosta, 2005), onde são apresentadas as ideias de Getz (1997, apud Silva, 2005), para termos aqui um conceito de megaeventos esportivos. Segundo esse pesquisador,

seu volume (dos megaeventos esportivos) deveria exceder um milhão de visitantes, seu orçamento deveria ser de, pelo menos, US\$ 500 milhões e sua reputação deveria ser de um evento imperdível. (...) Megaeventos, por sua grandiosidade ou significado, são aqueles que produzem níveis extraordinariamente altos de turismo, cobertura da mídia, prestígio ou impacto econômico para a comunidade local ou de destino.

Hall (apud Silva, 2005), outro pesquisador citado pela Atlas do esporte no Brasil, acrescenta que 
megaeventos tais como as feiras mundiais e exposições, a copa do mundo ou as olimpíadas são eventos especificamente direcionados para o mercado de turismo internacional e podem ser adequadamente descritos como "mega". [Isso] em virtude de sua grandiosidade em termos de público, mercado-alvo, nível de envolvimento financeiro, do setor público, efeitos políticos, extensão de cobertura televisiva, construção de instalações e impacto sobre o sistema econômico e social da comunidade anfitriã.

Por fim, não se pode ignorar que, em virtude dessa natureza aqui exposta, um megaevento esportivo é reconhecido, como pontua Maurice Roche (apud Silva, 2005), como "um evento de produção da mídia", com impactos político, econômico e tecnológico. É justamente pelo seu poder midiático de congregar telespectadores pelo mundo todo e de expor ideias, lugares e pessoas que uma copa do mundo, por exemplo, pode ser uma excelente oportunidade para dar visibilidade a um país, um estado ou uma cidade com vocação para o turismo. Uma das formas de se ativar essa sedução imagética pode ser pela exibição de pratos gastronômicos típicos.

Por essa breve explicação, cabe lembrar que, sendo assim, é fundamental criar uma imagem atraente para os turistas e, especialmente, mostrar aos patrocinadores e investidores que aquele evento foi bem organizado. E, não menos importante, os organizadores devem também criar uma imagem positiva e atraente do país-sede, podendo a gastronomia atuar como uma das ferramentas que possibilita tal construção. Os pratos típicos de um país podem contribuir para a experiência do viajante e também para o show de imagens midiáticas que se faz em torno dos megaeventos esportivos.

Ainda sobre a aproximação entre esporte, gastronomia e turismo, lembramos as ideias do semioticista Lotman (1996). Para ele, a imagem criada pela marca de um país, associando elementos distintos, seria formulada e mantida por meio de interações, mostrando sistemas que atuam em constantes trocas, em uma comunicação no espaço fronteiriço dos sistemas. Nesse processo comunicativo, o autor define que a fronteira não é um limite que separa dois espaços diferentes, mas, sim, um espaço de intersecção onde se dá a passagem e a integração de elementos opostos. Na construção da identidade de país, a troca de informações por meio da fronteira dos sistemas da cultura é responsável pelo enriquecimento das imagens-síntese que surgem.

Considerando a organização como um dado sistema da cultura que troca informação com outros sistemas, usamos conceitos da semiótica da cultura para mostrar que a marca-imagem de um país é um sistema estruturado em uma determinada cultura, mas sempre em constante transformação e que depende de interações entre sistemas para construir seus textos. Lotman (1996, p. 89) defende mesmo que os textos da cultura atuam como portadores da memória da cultura -isso explicaria por que as imagens da gastronomia se consolidam de tal maneira que são capazes de representar a cultura de um país: 
La capacidad que tienen distintos textos que llegan hasta nosotros de la profundidad de oscuro passado cultural, de reconstruir capas enteras de cultura, de restaurar el recuerdo, es demostrada patentemente por toda la historia de la cultura de la humanidad. No sólo metafóricamente podríamos comparar los textos con las semillas de las plantas, capaces de conservar y reproducir el recuerdo de estructuras pendentes. En este sentido los textos tienden a la simbolización y se convierten en símbolos integrales.

Na construção da imagem-marca de um país, pesam fatores como a cultura da organização e, especialmente, a cultura onde essa organização está inserida. Considerando que, ao ser escolhido como país sede da Copa de 2014, o Brasil passou a desenvolver projetos para construção física de arenas e outras obras de infraestrutura a fim de sediar o evento, é fundamental considerar que, no mesmo momento da escolha, iniciou-se um processo de construção simbólica desse país-sede.

Assim, é praxe que a mídia trabalhe com as características geográficas e culturais dos países-sede. Na Copa da África, em 2010, várias matérias jornalísticas em todos os meios de comunicação abordaram as maravilhas naturais daquele país; outras reportagens focaram nas diferenças culturais do país, nos problemas com o racismo, como as heranças do apartheid, e no tema que nos interessa nesta comunicação: na gastronomia da Africa do Sul. Lembrando que todo megaevento possui um comitê organizador, é tarefa deste fortalecer as relações com a imprensa a fim de divulgar a imagem do país-sede, fortalecendo símbolos e imagens mais fortes e adequadas àquele planejamento de comunicação.

Nesse sentido, a marca de um país reflete o modo como uma entidade social confere sentido a si mesmo em relação à cultura da qual ela faz parte. Ana Luisa de C. Almeida (2009, p. 219) pontua que

os atributos que definem a essência de uma organização e são utilizados como forma de sua representação têm maior adesão quando há um entendimento por parte de seus públicos de que tais atributos expressam elementos de sua cultura, seus valores e seus princípios.

Assim, tomando a ideia de organização para aproximar a complexidade da realidade de um país e a construção de sua imagem pública, consideramos que a cultura gera textos que criam imagens simbólicas. Desse modo os símbolos da gastronomia criam imagens que representam a identidade organizacional do Brasil como país-sede da Copa do Mundo de 2014.

\section{GASTRONOMIA COMO TEXTO DA CULTURA}

A gastronomia, segundo Algranti (2000, p. 252), é a "arte de cozinhar de maneira a proporcionar o maior prazer a quem come, de regalar-se com finos 
acepipes e iguarias" e consideramos que se trata de uma linguagem derivada do mundo da cozinha. Assim, se a gastronomia típica do Brasil é uma linguagem da cozinha, os textos por ela gerados - receitas, pratos, restaurantes - usam como códigos os alimentos típicos do Brasil e os saberes técnicos da culinária brasileira para construir símbolos da nossa cultura. A gastronomia constitui um universo que vai além da necessidade biológica do ser humano de se alimentar; ela envolve prazer em preparar e em degustar o alimento e, portanto, acrescenta novas camadas de significação ao ato de comer.

No caso da comida típica brasileira, é fundamental observar que os pratos típicos que levam a imagem do Brasil para outros países, como as já citadas feijoada e caipirinha, entre outros, são resultado do encontro das culturas que formaram a cultura brasileira: portugueses, negros e índios, sem falar das imigrações do final do século XIX e começo do século XX.

Sobre esses encontros culturais de diversos povos, como os que formaram a cultura brasileira e, por conseguinte, a sua comida, as palavras de Lotman (1996, p. 90) sobre a riqueza que pode resultar desse processo são elucidativas quanto à força que esse tipo de texto da cultura formadora de imagens pode tomar:

Podríamos decir que el contacto con otra cultura desempeña el papel de un mecanismo de arranque que pone en marcha procesos generativos. La memoria del hombre que entra en contacto con el texto puede ser considerada como un texto complejo, el contacto con el cual conduce a cambios creadores en la cadena informacional.

Nesse contexto podemos destacar que as imagens da gastronomia tipicamente brasileira são esses textos complexos de que fala Lotman, capazes de construir símbolos fortes o bastante para serem usados pelas organizações como símbolos de identidade.

É importante lembrar que o conceito de comidas típicas é naturalmente constituído por imagens ideais, pratos reservados para ocasiões especiais, mas que por sua diferenciação natural acabam por constituir comidas perfeitas para compor esses textos simbólicos complexos. Como diria Cascudo (1983, p. 369), "o povo não come galinha assada com recheio, peixe sem espinhas ao molho branco, coquetéis de camarão, lagosta com mayonnaise. Come carne, farinha, feijão, arroz".

Lépine (apud Kominsky; Lépine; Peixoto, 2003, p. 295), em obra que destaca o trabalho do sociólogo Gilberto Freyre na defesa da comida típica brasilei$\mathrm{ra}^{4}$, afirmam que a alimentação de um povo define um símbolo importante da sua cultura:

4 Para mais detalhes sobre a obra de Gilberto Freyre, gastronomia e cultura brasileira, ver Jacob (2066). 
A alimentação representa um elemento fundamental da cultura nacional, um espaço privilegiado onde se manifestam as particularidades culturais, reivindicações regionais ou nacionais. A classificação dos alimentos em comestíveis ou não, quentes ou frios, cozidos ou crus, assados ou fervidos, por exemplo, constitui um sistema integrado próprio de cada civilização e cria gostos que definem fronteiras alimentares. Fronteiras alimentares fortes constituem fronteiras socioculturais fortes.

A definição de comida do Brasil dada por Freyre é a da exuberante em cores, sabores e texturas. $\mathrm{O}$ autor criou uma imagem dessa cozinha que ainda persiste e corresponde tanto a uma realidade quanto a um estereótipo. A indústria do turismo costuma utilizar esta comida exuberante, colorida e até exótica. No caso da imagem de um país-sede de um megaevento esportivo, esse processo se repete e tais símbolos constituem elementos de constituição primordial, pois farão a comunicação de como esse país se constitui. Assim a organização país-sede constrói sua imagem para os públicos de interesse.

Utilizar a gastronomia como símbolo dos valores turísticos de um país é uma prática corrente e antiga. A comunicação de órgãos de incentivo ao turismo de vários locais do mundo enfatiza que se podem conhecer determinados locais e apreciar a comida, sempre uma experiência agradável. Em relação à área de eventos, atividade importante das práticas da comunicação organizacional, pode-se mesmo falar de um turismo de eventos, segundo Reis (2008, p. 509):

Uma das mais procurados formas de promoção do turismo da sociedade contemporânea é a apresentação de eventos. Eles representam uma forma singular de exibição para suas sedes, estendendo seus nomes e hábitos através da região, da nação ou do mundo, dependendo de seu tamanho e natureza. Turismo de eventos é definido como "a sistematização do desenvolvimento e do marketing de eventos como atração turística” (Getz, 1989, p. 133).

Nessa maximização de atrativos para os turistas, destacamos o papel da gastronomia, pela atração e pela necessidade que a comida exerce, bem como pela força que tais imagens podem ter para que se construa a imagem organizacional do país-sede. No site oficial do turismo da África do Sul, por exemplo, país-sede da Copa do Mundo de 2010, a gastronomia faz parte do menu "O que fazer/A vibração urbana" com o nome de "Comida e vinho"'. Neste link o internauta acessa algumas dicas de lugares para comer e, principalmente, um roteiro de vinhos sul-africanos. Afinal, o vinho é um dos produtos mais nobres da gastronomia e, como a África do Sul tem conseguido bom nível no mercado vinícola, destacar esses roteiros faz parte da estratégia promocional do turismo desse país.

Um país, ao criar sites, redes sociais, revistas e outras ferramentas de comunicação para falar com seus públicos - tanto turistas quanto possíveis investido-

5 Ver: <http://www.southafrica.net/sat/content/br/br/brazil-food-and-wine $>$. 
res e empresários -, está fortalecendo sua imagem criando canais de relacionamento com tais públicos. Ao fazer isso, ele está utilizando o princípio número um do trabalho de relações públicas. Na interligação entre esportes e relações públicas, os profissionais responsáveis pela construção e manutenção dos relacionamentos das organizações com seus públicos, o Dicionário enciclopédico Tubino do esporte (2007, p. 722) destaca que é objetivo do relações-públicas a "criação de uma imagem positiva por meio de atendimento qualificado, ou seja, de uma comunicação adequada ao público-alvo, também com a preocupação de responsabilidade social”.

Ainda segundo esse dicionário, o universo das relações públicas no esporte compreende campanhas, eventos, relacionamento, publicações, estratégias comunicacionais e fortalecimento da imagem. Nesse contexto, acreditamos que os profissionais de relações públicas podem ter um excelente papel na construção de imagem do Brasil como país-sede da Copa do Mundo de 2014, por meio das imagens da gastronomia tipicamente brasileira.

\section{CONSIDERAÇÕES FINAIS}

Buscamos fazer neste artigo uma aproximação teórica entre a gastronomia e os megaeventos esportivos, sob o viés das estratégias de construção de imagem e da marca de um país. A nossa defesa é que, em oportunidades como as geradas pela Copa do Mundo de Futebol, os profissionais de relações públicas podem desenvolver ações para fortalecer a imagem-marca do Brasil, a partir de ações envolvendo os aspectos gastronômicos nacionais.

Ao longo do texto, buscamos conceituar imagem e marca-país, além de aproximar esses conceitos do universo dos megaeventos esportivos, por meio da gastronomia como manifestação da cultura. No processo de preparação do país para a Copa de 2014, ao longo desse ciclo, muitas iniciativas estão sendo desenvolvidas. O Ministério da Cultura, por exemplo, realizou o seminário "Intercâmbio de experiências culturais em megaeventos esportivos", no segundo semestre de $2011^{6}$, o que mostra que as ideias de se aproximar o universo cultural internacional da Copa do Mundo de 2014 podem ser viáveis e gerar bons frutos para o país.

Já o Ministério do Esporte abriu um edital chamado "Plano de promoção do Brasil", que tem como meta "a promoção do país de uma forma ampla. As ações de publicidade, de relações públicas, de promoção de imagem e de relacionamento com a imprensa são apontadas como indispensáveis ferramentas para garantir o sucesso do evento, especialmente para o fomento comercial, turístico e sociocultural"'.

6 Ver: <http://www.cultura.gov.br/site/2011/08/12/copa-do-mundo-2/>. Acesso em: 05/11/2011.

7 Ver: <http://www.copa2014.gov.br/noticia/comissao-do-plano-de-promocao-para-copa-reune-mais-de270-projetos > . Acesso em: 05/11/2011. 
No site do Ministério do Turismo já foi criado o link "Gastronomia”, especialmente para a Copa de 2014, com os perfis das doze cidades brasileiras que sediarão jogos do evento ${ }^{8}$. Por exemplo, no caso de São Paulo, definida como sede da abertura do Mundial de Futebol, o site destaca a diversidade da capital paulistana, conhecida pelo imaginário popular de seus moradores como "capital mundial da gastronomia:

Não é fácil agradar ao paladar de quase 11 milhões de pessoas, mas Sampa não deixa a desejar e oferece a mais variada rede gastronômica do Brasil, que vai desde comidas típicas de outros estados aos requintados e exóticos sabores de todas as partes do mundo. Existem 1.500 pizzarias espalhadas pela cidade, 500 churrascarias e 250 restaurantes japoneses.

Verifica-se no site do Ministério do Turismo a consolidação de imagens trabalhadas normalmente pela indústria turística nacional, do que é a comida brasileira e de como ela pode ser saboreada pelos turistas e participantes da Copa de 2014. Assim a comida baiana é "quente" (apimentada) e utiliza muito azeite de dendê e a de São Paulo prima pela diversidade e pelo viés cosmopolita. Tais exemplos mostram como a construção do papel e da identidade do Brasil como país-sede da Copa de 2014 utilizam ainda imagens simbólicas para construir a sua imagem organizacional, mas há muito o que se explorar em termos de gastronomia e cultura no fortalecimento da marca "Brasil".

É importante que o Brasil reafirme seus principais símbolos gastronômicos e os trabalhe como pontos-chave da comunicação com os públicos da Copa de 2014. Acreditamos que iniciativas como essa gerarão grandes oportunidades para o fortalecimento da imagem do país no mercado externo e até mesmo no interno. Por fim, destacamos que o trabalho das relações públicas é justamente a força motriz da construção dessa imagem: é o profissional da área que pode e deve fazer a construção desses canais de relacionamento, levando as imagens simbólicas da gastronomia brasileira a serem reforçadas na comunicação com os públicos de interesse da Copa de 2014.

\section{REFERÊNCIAS}

ALGRANTI, Márcia. Pequeno dicionário da gula. Rio de Janeiro: Record, 2000.

ALMEIDA, Ana Luisa de Castro. Identidade, imagem e reputação oprganizacional: conceitos e dimensões da práxis. In: KUNSCH, Margarida M. Krohling. Comunicação organizacional. Vol. 2. Linguagem, gestão e perspectivas. São Paulo: Saraiva, 2009.

BAUDRILLARD, Jean. Tela total: mitoironias da era do virtual e da imagem. Porto Alegre: Sulina, 2005.

CARVALHO, Mariana; LEMOS, Ricardo Leal. Quando os países se tornam marcas. Fora de Linha [on-line], Universidade Nova de Lisboa. Disponível em: < http://www.fcsh.unl.pt/cadeiras/plataforma/foralinha/atelier/a/www/view.asp?edicao=09\&artigo =372>. Acesso em: 01 nov. 2011.

CASCUDO, Luís da Câmara. História da alimentação no Brasil. Vol. I. São Paulo: Itatiaia, 1983.

8 Ver: <http://www.copa2014.turismo.gov.br/copa/home.html>. Acesso em: 05/11/2011. 
CATALÀ, Joseph M. La imagen compleja. Barcelona: Universitat Autónoma de Barcelona, 2005.

DaCOSTA, Lamartine P. (Org.). Atlas do esporte no Brasil: atlas do esporte; educação física e atividades físicas de saúde e lazer no Brasil. Rio de Janeiro: Shape, 2005. Também disponível: <http://www.atlasesportebrasil.org.br/index.php>.

DaCOSTA, Lamartine P. et. al. (Org.). Legado dos megaeventos esportivos. Brasília: Ministério dos Esportes-Confef, 2008.

DEBORD, Guy. A sociedade do espetáculo. Rio de Janeiro: Contraponto, 1997.

ELSBACH, Kimberly D. Managing organizational legitimacy in the California cattle industry: the construction and effectiveness of verbal accounts. Administrative Science Quarterly, v. 39, p. 57-88, 1994.

ENCICLOPÉDIA INTERCOM DE COMUNICAÇÃO. Vol. 1. São Paulo: Sociedade Brasileira de Estudos Interdisciplinares de Comunicação, 2010.

FIGUEIREDO NETO, Celso. Imagem da marca. In: MARQUES DE MELO et al. (Org). Enciclopédia Intercom de comunicação. São Paulo: Sociedade Brasileira de Estudos Interdisciplinares da Comunicação, 2010. Vol. 1. p. 655-656. GURGEL, Anderson. Futebol S/A: a economia em campo. São Paulo: Saraiva, 2006.

JACOB, Helena Maria A. Comer com os olhos: estudo das imagens da cozinha brasileira a partir da revista "Claudia Cozinha". Dissertação (Mestrado em Semiótica) - PUC-SP, São Paulo, 2006.

KOSMINSKY, Ethel V.; LÉPINE, Claude; PEIXOTO, Fernanda A. Gilberto Freyre em quatro tempos. São Paulo: Editora Unesp / Edusc, 2003.

KUNSCH, Margarida M. Krohling. Comunicação organizacional. Vol. 2. Linguagem, gestão e perspectivas. São Paulo: Saraiva, 2009. LOTMAN, Jurij M. La semiosfera I: semiótica de la cultura y del texto. Madrid: Editora Cátedra, 1996.

MENEZES, José E. de Oliveira. Imagem. In: MARQUES DE MELO et al. (Org). Enciclopédia Intercom de comunicação. São Paulo: Sociedade Brasileira de Estudos Interdisciplinares da Comunicação, 2010, v. 1, p. 652-653. REIS, Arianne C. Megaeventos e turismo: uma breve revisão. In: DaCOSTA, Lamartine P. et. al. (Org.). Legado dos megaeventos esportivos. Brasília: Ministério dos Esportes-Confef, 2008.

SAVARIN, Brillat. A fisiologia do gosto. São Paulo: Cia. das Letras, 1995.

SILVA, JOSÉ da. Gestão da segurança em megaeventos esportivos. In: DaCOSTA, Lamartine P. (Org.). Atlas do esporte no Brasil: atlas do esporte; educação física e atividades físicas de saúde e lazer no Brasil. Rio de Janeiro: Shape, 2005. Também disponível em: <http://www.atlasesportebrasil.org.br/index.php>.

TAGÉ, Terezinha. Contaminações textuais e discursivas na imprensa contemporânea. Rumores, São Paulo, USP, v. 2, p. 10, 2009.

TUBINO, Manoel José G.; TUBINO, Fábio Mazeron; GARRIDO, Fernando A. Cardoso. Dicionário enciclopédico Tubino do esporte. Rio de Janeiro: Senac- Rio, 2007.

UOL. Marca "Brasil" sobre dez posições em ranking de consultoria. 11/11/2011. Disponível em: <http://noticias.uol.com.br/ bbc/2011/11/11/marca-brasil-sobe-dez-posicoes-em-ranking-de-consultoria.jhtm >. Acesso em: 11 nov. 2011.

Recebido em: 12/09/2011 / Aceito em: 11/11/2011 